\title{
ENTENDIMIENTO AGENTE Y ABSTRACCIÓN EN DUNS ESCOTO
}

\author{
Antonio Pérez-Estévez \\ Universidad del Zulia (Venezuela)
}

\section{RESUMEN}

Duns Escoto siguiendo el principio de que «sin fantasma no hay conocimiento sensible y sin especie inteligible no hay intelección», defiende la necesidad de la existencia del entendimiento agente para poder explicar el paso del conocimiento particular al conocimiento universal. El conocimiento universal objetivo se produce en dos momentos: en el primero, el entendimiento agente, como causa efectiva principal, y la naturaleza común representada en el fantasma, como concausa efectiva, producen la especie inteligible, universal indeterminado en acto o universal metafísico; en el segundo momento, el entendimiento posible, como causa efectiva principal, y la especie inteligible, como causa efectiva instrumental, producen la intelección, universal completo o universal lógico, encarnado en un concepto y un nombre universal. El universal completo o lógico, reducido a un concepto y un nombre predicable de muchos, es una segunda intención que remite, inmediatamente, al universal indeterminado en acto o especie inteligible -intención primera- $y$, mediatamente, al fantasma representativo del individuo real.

Palabras claves: Duns Escoto, teoría del conocimiento, entendimiento agente, universal, abstracción.

\begin{abstract}
Duns Scotus, following the saying that «without the phantasma there is no sensible knowledge and without the intelligible species there is no intellection», argues for the need of an active intellect in order to explain the transit from the particular to the universal knowledge. The universal knowledge from experience takes place in two different moments: first, the active intellect, as the main effective cause, together with the common nature in the phantasma, as the co-effective cause, produce the intelligible species, that is, the indeterminate universal in act or the metaphysical universal; second, the passive intellect, as the main effective cause, and the intelligibible species, as the effective instrumental cause, produce the intellection, that is, the full universal or the logic universal, that is a universal concept and name. The full universal or logical universal, is only a concept and a name that can be said of many individuals. It is a second intention that refers, immediately, to the first intention or intelligible species and, indirectly, to the phantasma, the representative of the physical individual.
\end{abstract}

Key Words: Duns Scot, Knowledge, Active Intellect, Universal, Abstraction.

\section{ENTENDIMIENTO AGENTE EN ARISTÓTELES}

Toda la doctrina sobre el entendimiento agente que se elaboró en los largos siglos medievales, tiene su raíz en un texto del De Anima de Aristóteles $\left(430^{\mathrm{a}} 10-25\right)^{1}$. Texto corto que será

1 Aristóteles, De Anima, translation, introductions and notes by R. D. Hicks, Georg Olms Verlag, HildesheimZürich-New York, 1990. 
leído y releído, interpretado y reinterpretado centenares de veces. En palabras de W.D. Ross, la doctrina (del entendimiento agente) «es quizás la más oscura y ciertamente la más discutida de todas las doctrinas de Aristóteles» ${ }^{2}$. No es mucho lo que Aristóteles nos dice sobre el entendimiento agente, pero es importante conocerlo, para poder compararlo con lo que los distintos autores medievales dirán sobre el tema.

Comienza diciendo $\left(430^{\mathrm{a}} 10-14\right)$ que

«de manera semejante a como en toda la naturaleza hay algo como la materia para cada tipo de cosas, la cuál es en potencia cada ejemplar de estos tipos de cosas, y hay también una causa activa que hace todas las cosas, análoga a la relación de la técnica o arte de hacer cosas con respecto a su materia, asi en el alma deberán existir estas dos diferencias».

Parece Aristóteles, en este texto, aplicar al alma la doctrina hilemórfica que ha aplicado a todas las sustancias de la naturaleza. En el alma habrá de darse algo que haga de materia

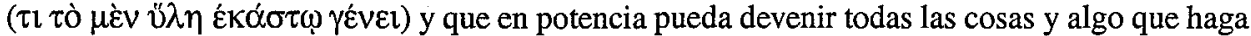
de causa activa (

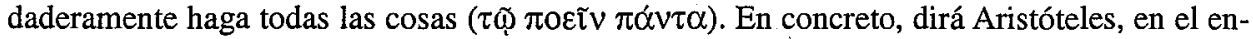
tendimiento ( $(00 \zeta)$ o capacidad de conocer lo inteligible distinguiremos un entendimiento que

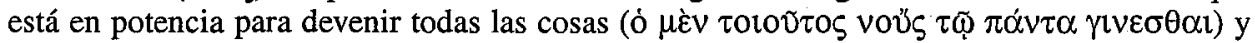
un entendimiento que hace todas las cosas $(\tau \emptyset \pi$ o devenir todas las cosas, ya había dicho que

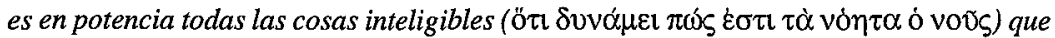
son las cosas materiales pero sin su materia.

Había dicho también de este entendimiento que es el lugar de las ideas, las cuales están en él sólo en potencia. Del entendimiento que hace todas las cosas dice que es

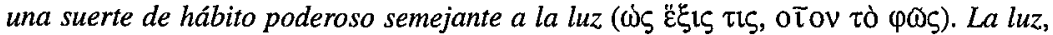
añade, de alguna manera hace que los entes colorados en potencia sean coloradas en acto. Es este entendimiento separable, impasible y sin mezcla, siendo en su esencia actualidad $\left(430^{\mathrm{a}} 115-118\right)$.

Después de afirmar que «lo que actúa es siempre superior a aquello sobre lo que actúa y el principio superior a la materia» terminará diciendo del entendimiento actual que

«no puede pensar y dejar de pensar y sólo separado es el mismo y este sólo es inmortal

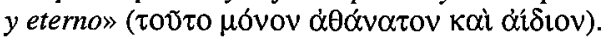

El entendimiento que puede ser afectado o pasivo es perecedero y sin éste no conoce nada $>\left(430^{\mathrm{a}} 22-25\right)$.

Intentemos resumir lo dicho en el párrafo anterior. Aristóteles distingue en la facultad cognoscitiva del alma un entendimiento pasivo y un entendimiento activo que vienen a ser como la materia y la forma en el proceso de conocer. El entendimiento pasivo es, antes de conocer, sólo potencia, lo que significa que por sí solo no puede conocer; el entendimiento activo es sólo actualidad y, por tanto, no puede dejar de conocer. El entendimiento pasivo es en potencia todas las cosas inteligibles, que son las cosas pero sin su materia, o, dicho de otra forma, es el lugar de las ideas que están en él solo en potencia; este entendimiento es además perecedero y, en 
el individuo, anterior en el tiempo al entendimiento activo, aunque en general sea el activo anterior. El entendimiento activo, por el contrario, es separable, inmortal y eterno. Dos son las analogías que Aristóteles ofrece del entendimiento activo: en la primera dice que es semejante a la técnica o capacidad de hacer cosas con respecto a su materia; en la segunda, dice que es semejante a la luz, la cual hace que las cosas coloradas en potencia se conviertan en coloradas en acto. En realidad, estas dos analogías son tan similares que pueden reducirse a una sola, a saber, que el entendimiento agente, como la técnica y como la luz, hace que los entes que son inteligibles en potencia se conviertan en inteligibles en acto. Los dos entendimientos, el pasivo y el activo, son separables de la materia, pero mientras el pasivo es perecedero, incapaz por sí solo de pensar y anterior en el tiempo en el individuo, el activo es inmortal y eterno y, en general, como pura actualidad que no puede dejar de pensar, anterior al pasivo.

De este pequeño texto saldrán centenares de lecturas e interpretaciones distintas en los largos siglos medievales. Alejandro de Afrodisia, Plotino, Temistio, Juan de Filopón servirán de intermediarios entre el texto aristotélico y los grandes autores árabes, Alfarabí, Avicena y Averroes $^{3}$. En este tránsito, el entendimiento agente pasará de ser el productor de los objetos inteligibles en el alma humana a ser un entendimiento cósmico o una realidad transcendente y celeste, más o menos cercana de la Causa Primera e intermediaria entre ésta y el mundo sublunar. Estos autores árabes, a su vez, servirán de puente a través del cuál el texto de De Anima llegará a los pensadores cristianos del siglo XIII. La teoría de la iluminación que encontramos, dentro de la tradición agustiniana, en autores franciscanos como Buenaventura o Pecham, mantiene la marca de esta importante corriente neoplatónica

\section{NECESIDAD DEL ENTENDIMIENTO AGENTE EN DUNS ESCOTO}

Duns Escoto abandona el injerto neoplatónico del entendimiento agente como sustancia cósmica, intermedia entre Dios o la Causa primera y el mundo sublunar, y reduce la realidad del entendimiento agente al elemento activo de la parte intelectiva del alma humana. La función del entendimiento agente es exclusivamente epistémica y se desarrolla dentro de la facultad intelectiva del alma humana. Es decir, retoma la aplicación aristotélica del hilemorfismo y distingue en la facultad intelectiva del alma humana algo que está en acto y es activo a lo que llama entendimiento agente, y algo que está en potencia a lo que llama entendimiento posible o pasivo y es receptivo. De hecho, cita el $D e$ Anima, cap. 3 para recordar que

el entendimiento agente es una facultad verdaderamente activa, porque expresa aquello que es para hacer todo y porque expresa lo que tiene una relación semejante a la que tiene el arte con la materia ${ }^{4}$.

Para Duns Escoto el conocimiento humano a partir de la experiencia sensible ${ }^{5}$ constituye un proceso unitario con dos momentos esenciales en cada uno de los cuáles se da un acto de conocer distinto, a saber: a) el acto de conocimiento sensible por medio de los órganos de los

3 Ver Herbert A. Davidson: Alfarabi, Avicenna and Averroes on Intellect, Oxford University Press, New YorkOxford, 1992, pp. 7-43.

4 Opera Omnia. Reportata Parisiensia, Edición Vives, París, 1894, tomo 22, Liber I, dist. III, q.IV, p. 102: Intellectus agens est potentia vere activa secundum Philosophum De anima, cap. 3, tum quia dicit illud, quod est omnia facere; tum quia dicit quod se habet ut ars ad materiam...Intellectus agens respectu possibilis adaequatur secundum Philosophum, 3 de Anima cap. 3, ut activum passivo, quia quando causat pro primo effectu est in adaequato passivo...

5 Duns Escoto distingue tres tipos de cognoscibles: 1) principios per se nota y conclusiones, de principiis per se notis et de conclusionibus, 2) lo conocido por medio de la experiencia, de cognistis per experientiam, 3) conocimiento de nuestras acciones, de actibus nostris (Ordinatio I, dist. 3, pars I, q. 4, p. 138, No. 239. 
sentidos externos, interno e imaginación con el fin de producir el fantasma u objeto intencional de la sensibilidad; b) el conocimiento intelectivo objetivo en el que participan el entendimiento agente y el entendimiento pasivo. El entendimiento agente es un elemento esencial en el momento intelectivo del conocer por medio de la experiencia en el ser humano. Sin los sentidos, externos e interno, y sin la imaginación o fantasía sería imposible explicar la existencia del fantasma u objeto intencional del conocimiento sensible, semejante a los objetos que se encuentran en el mundo de la experiencia sensible. Sin el entendimiento agente, sería imposible explicar la existencia de las especies inteligibles, que son el objeto intencional, inmediato y necesario para que se produzca el concepto correspondiente en la parte intelectiva del alma humana; conceptos que son el contenido de toda operación intelectiva en el ser humano. Sin objeto sensible o fantasma no hay conocimiento sensible; sin objeto universal o especie inteligible no hay intelección ${ }^{6}$.

Partiendo de la necesidad de la especie inteligible y del entendimiento agente en el proceso de conocer, Duns Escoto rechaza toda opinión que se oponga o debilite dicha necesidad. Se opondrá, en consecuencia, a todo residuo platónico que, aceptando algún tipo de esencias abstractas, elimine, en el proceso de conocer, la especie inteligible como derivada del fantasma y, con ella, el entendimiento agente ${ }^{7}$.

En su tiempo el representante más destacado de esta doctrina platonizante era Enrique de Gante. Basándose en textos de Super Genesim y De Trinitate de Agustín de Hipona, defenderá que los conceptos o ideas no provienen de los fantasmas sensibles producidos por los sentidos sino que

\section{«el alma misma forma en sí misma las imágenes de las cosas conocidas» ${ }^{8}$.}

Siguiendo a Platón, dirá que los fantasmas son sólo la ocasión para que el alma misma sea la causa total de la intelección o la razón de producir los conceptos, ut ratione gignendi. Un argumento que justifica esta opinión se basa en que

«el efecto no puede exceder a su causa en perfección y la operación intelectiva es una acción vital que no puede provenir sino de un principio vital como el alma humana».

Otra razón deriva de que el alma humana, en cuanto es la más perfecta de todas las formas es también la más actual y la más activa. Con ocasión de un fantasma, el alma se mueve a sí misma en su operación y produce en sí misma el concepto o idea ${ }^{10}$. Finalmente, la intelección es, en esta concepción, una acción inmanente y permanece en la parte intelectiva del alma misma ${ }^{11}$, sin que precise para dicha acción del fantasma ni de la especie inteligible como causa.

6 Lectura I, Edición Vaticana, 1960, dist. 3, parte 3, q. 1, p. 332, No.267: ...prius naturaliter objectum est praesens intellectui quam actus eliciatur; ergo intellectus habet objectum universale sibi praesens in ratione speciei intelligibilis prioris natualiter actu intelligendi.

7 Reportata Parisiensia, Liber I, dist. III, q. IV, p. 102: si enim essentiae rerum essent abstractae, sicut posuit Plato, non indigeremus, secundum ipsum, intellectu agente.

8 Opera Omnia. Quaestiones In Librum I Sententiarum, Edición Vives, Paris, 1893, tomo IX, dist. III, q. VII, p. 338: ipsa anima in se format imagines ipsorum cognitorum, ut dicit ista auctoritas...

9 Opera Omnia. Quaestiones in Primum Librum Sententiarum, Edición Vives, tomo IX, dist. 3, q. 7, p. 338: Pro ista opinione arguit per rationes sic: effectus non excedit causam in perfectione, melius est autem omne vivum non vivente, secundum Augustinum de Civitate, ergo operatio vitalis non potest esse nisi a principio agendi. vitali, vel vivo: istae operationes cognoscendi sunt operationes vitales, ergo sunt ab ipsa anima sicut a ratione gignendi.

10 Quaestiones in Primum Librum Sententiarum, p. 338: anima intellectiva inter omnes formas est actualissima, ergo maxime activa. Igitur se habet in ratione activi, et se sola seipsam movet in operatione sua...

11 Quaestiones In I Librum Sententiarum, p. 338: intellectio igitur proprie est operatio manens in agente; manet autem in parte intellectiva... 
Duns Escoto echa mano de algunos textos de Agustín, pero, sobre todo, echa mano de la razón para refutar la opinión de Enrique de Gante. En efecto, si el alma humana en su potencia intelectiva se basta como causa activa y como sujeto receptivo para producir la intelección, su parte intelectiva no dejará jamás de entender, de tener una intelección actual ${ }^{12}$. Si la parte intelectiva del alma se basta a sí misma para entender, no hay razón alguna para que no esté siempre entendiendo en acto, como querrá más tarde Descartes, lo que va en contra de nuestra experiencia cotidiana. Según esta experiencia, entender o conocer algo inteligible supone pasar de un estado de no actividad o de no conocer a otro de actividad o de conocimiento intelectual. Además, si la potencia intelectiva del alma se basta sola para entender o conocer algo inteligible, sin precisar del fantasma y del conocimiento sensible como causa parcial, difícilmente se explica la objetividad de tal conocimiento y difícilmente podremos distinguir entre conocimiento objetivo y no objetivo.

Duns Escoto está también en contra de la opinión contraria, defendida por Godofredo de Fontaines, a saber, que

«ninguna actividad o causalidad realiza el alma, en cuanto intelectiva, con respecto a la intelección» 13 .

En la parte intelectiva del alma no puede distinguirse un entendimiento agente y un entendimiento posible, como tampoco el mismo sujeto puede estar (a la vez) en acto y en potencia. En consecuencia, el entendimiento agente nada puede causar en el posible ya que no se distinguen en la facultad intelectiva. Y si el alma no es en absoluto causa de la intelección, tendrá que ser el objeto, en cuanto reluce en el fantasma iluminado formalmente por el entendimiento agente, la causa eficiente de la intelección y de la volición ${ }^{14}$. El entendimiento agente, en esta opinión de Godofredo de Fontaines, no es causa de nada formal en el fantasma. $\mathrm{Su}$ acción, por medio de una suerte de contacto espiritual que ilumina al fantasma, se reduce a eliminar los obstáculos y, de esa forma, el entendimiento posible se convierte en informado ${ }^{15}$. La facultad intelectiva en cuanto intelectiva no comprende ni al entendimiento agente ni al posible y nada tiene de activo o de agente con respecto a la intelección. De ahí que sólo el fantasma sea la única causa efectiva de la intelección; y si alguna eficiencia de iluminación se produce sobre el fantasma, ésta provendrá del mismo Dios quien creó tal luz en el entendimiento posible. Nada distinto de Dios, a no ser sólo el fantasma, dice relación activa a cualquier intelección ${ }^{16}$. Esta doctrina difícilmente puede explicar la actividad intelectiva del alma no derivada directamente de un fantasma y de un objeto exterior sensible, tal como el conocimiento de los primeros principios y la operaciones lógicas argumentativas como la inferencia.

Ambas opiniones, la de Enrique de Gante por exceso de actividad en la potencia intelectiva del alma y la de Godofredo de Fontaines por defecto de actividad intelectiva, no necesitan, en el proceso intelectivo de conocer, ni la especie inteligible ni, por tanto, el entendimiento

12 Quaestiones In I Librum Sententiarum, p. 339: si anima est totalis causa activa notitiae genitae, et ipsa est materia disposita, sive subjectum receptivum vel susceptivum respectu eiusdem, et ipsa est semper actu presens cum sit causa naturalis, semper erit actualis intellectio in ea...

13 Quaestiones In I Librum Sententiarum, p. 345: anima intellectiva ut intellectiva est, nihil habet activitatis vel causalitatis respectu intellectionis.

14 Quaestiones In I Librum Sententiarum, p. 346: objectum idem secundum rem efficit intellectionem et volitionem, et hoc inquantum relucet in phantasmate illustrato ab intellectu agente, non effective sed formalilter concurrente respectu intelligibilis.

15 Quaestiones In I Librum Sententiarum, p. 347: intellectus secundum eum, nihil causat quod sit formaliter in phantasmate, sed solum fit remotio prohibentium per quemdam contactum spiritualem huius lucis ad phantasmata, qua remotione facta, virtute intellectus agentis fit informatus intellectus possibilis.

16 Quaestiones In I Librum Sententiarum, p. 347: Si sit ibi efficientia aliqua per quam effective fiat irradiatio, vel illustratio super phantasmata, illa efficientia erit praecise ipsius Dei qui creavit lumen in intellectu possibili...nihil ergo aliud a Deo se habet active respectu intellectionis cuiuscumque, nisi phantasma solum. 
agente. Pero ambas opiniones, al decir de Duns Escoto, no explican verdaderamente el proceso intelectivo objetivo que consiste en pasar del conocimiento sensible y particular al conocimiento inteligible universal. Para Enrique de Gante, la intelección universal no proviene del fantasma como concausa sino que es totalmente producida por la actividad del alma; no se da, por tanto, paso de lo singular a lo universal. Para Godofredo, por el contrario, es sólo el fantasma particular, en unión con la directa iluminación proveniente de Dios, el que produce la intelección universal; aquí se salta de repente del fantasma particular a la intelección universal y se acude a Dios como a una suerte de Deus est machina para justificar ese salto. Para Duns Escoto, es absolutamente necesario acudir a la existencia del entendimiento agente y a la producción por el mismo de la especie inteligible como objeto universal intencional a partir del fantasma, para poder dar una correcta explicación del proceso intelectivo de conocer cosas, es decir, para explicar el paso de lo individual sensible a lo universal inteligible. A ese paso de lo individual sensible a lo universal inteligible se le conoce con el nombre de abstracción. Abstracción que, por otra parte, no significa lo mismo en el aristotelismo tomista que en Duns Escoto, como veremos con detalle más adelante.

\section{EL PROCESO ABSTRACTIVO COMO PASO DE LO INDIVIDUAL SENSIBLE A LO UNIVERSAL INTELIGIBLE.}

$\mathrm{El}$ proceso de conocimiento intelectivo a partir de la experiencia sensible, hemos dicho, es un proceso unitario con dos momentos: 1) el momento del conocer sensible por el que nuestra imaginación, en base a los datos provenientes de nuestros sentidos, produce el fantasma $\mathrm{u}$ objeto intencional, representativo de la cosa individual exterior sensible que afecta nuestros sentidos. 2) el momento del conocer intelectivo por el que nuestro entendimiento (agente y posible) producen primero la especie inteligible o el objeto inteligible intencional representativo del fantasma u objeto intencional sensible y luego, en un segundo paso, el concepto mismo universal con su nombre correspondiente, predicable de muchos individuos que se guarda en el entendimiento posible. En este proceso de abstracción se pasa, como vemos, del individuo singular sensible al universal inteligible.

\subsection{El individuo natural o sensible ${ }^{17}$}

Comencemos por comprender qué entiende Duns Escoto por «individuo sensible» que coincide con el concepto de sustancia individual sensible. Todo lo existente en el mundo físico es singular, pero no todo en el singular o individual es absolutamente singular. En todo singular existen realidades que pueden no ser en sí mismas singulares o individuales. Para entender este dicho, es preciso recordar que, para Duns Escoto, el individuo sensible es un compuesto de «naturaleza común y heceidad», términos que intentaremos explicar de inmediato.

La naturaleza común existe en la realidad extra-mental en cada una de las sustancias naturales del universo, constituyendo su quididad o esencia real, tal como es expresada en la definición ${ }^{18}$. La naturaleza existente en cada sustancia natural no es, por sí misma, individual, es

17 Para un estudio detallado del individuo, ver: Pérez-Estévez, Antonio, «El Individuo en Duns Scoto», Cuadernos Salmantinos de Filosofia, XXIII, 1996, pp.87-146.

18 Ordinatio II, Edición Vaticana, 1954, dist. 3, parte 1, q. 1, p. 410: communitas convenit naturae extra intellectum... et communitas convenit ex se naturae...

También: Ordintatio II, 3, 1, 1, p. 404: ita in re extra, ubi natura est cum singularitate, non est illa natura de se determinata ad singularitatem...

Ordinatio II, $3,1,5-6$, p. 485 , No. 190: universaliter enim, quaecumquue natura non est de se haec sed determinabilis ad essendum haec... 
decir, no posee la unidad real perfecta del individuo sino que posee una unidad real menor que la individual. Esto significa que la naturaleza común, posee una realidad imperfecta en cada sustancia natural que no le permite existir sola como individuo. Por eso, Duns Escoto la llama «naturaleza común» porque expresa la quididad o esencia común a todos los individuos de la misma especie. Al no poseer una unidad real perfecta o individual —ella misma es o puede ser un compuesto de múltiples unidades reales imperfectas o menores que la unidad individuales una realidad imperfecta que se encuentra en disposición de indiferencia para devenir ya sea un individuo en la realidad ya sea un universal en el entendimiento humano, sin que por sí misma sea ni individual ni universal ${ }^{19}$. La indiferencia es la característica esencial de la naturaleza común, la cual existe como realidad imperfecta en cada sustancia individual y, en sí misma, es por naturaleza anterior e indiferente a convertirse en singular, unida a la heceidad, o a convertirse en universal en y por obra del entendimiento humano. Unida a la heceidad, la naturaleza común se convierte en 'esta naturaleza individual'; elaborada por el entendimiento, se convierte en el concepto con su nombre, verdadero universal predicable de muchos ${ }^{20}$. La naturaleza común no es, por sí misma, ni universal ni individual, aunque pueda llegar a ser ambas cosas. En el caso concreto del individuo sensible o sustancia natural, la naturaleza común, sin dejar en sí misma de ser común e indiferente, se convierte en esta naturaleza individual por el añadido recibido de la heceidad.

La heceidad es una entidad positiva, una formalidad y un acto (Lectura) ${ }^{21}$ o cuasi acto o la última realidad de la forma (Ordinatio) ${ }^{22}$ que, añadida a la naturaleza común, la contrae, la determina y la perfecciona hasta convertirla en esta naturaleza individual, en una sustancia con una unidad perfectísima que la hace indivisible ${ }^{23}$. La heceidad es esencialmente singular y diversa de todo lo demás y hace que la naturaleza se singularice y se convierta en una sustancia individual, la cual, en cuanto singular, es indivisible y diversa de todas las demás.

Resumiendo, diremos que el individuo está constituido por la unión de la naturaleza común o esencia específica, en sí misma indiferente a devenir singular o universal, y la heceidad o formalidad que la torna indivisible y esencialmente diversa de todos los demás individuos de la misma especie.

Hemos de advertir que en el individuo - naturaleza común + heceidad- que es singular, se conserva, con su propia realidad disminuida, la naturaleza común que, por sí misma, continúa siendo indiferente, lo que implica posibilidad de ser tanto singular como su opuesto, a saber, universal. Esta indiferencia es lo que le permite devenir singular en unión de la heceidad o universal por obra de la acción del entendimiento. Duns Escoto llama a esta naturaleza común que, por sí misma, es indiferente, el universal in re o universal real, base del universal metafísico y del universal lógico de los que hablaremos más tarde.

19 Ordinatio II, 3, 1, 1, p. 403: licet enim numquam sit realiter sine aliquo istorum, de se tamen non est aliquod istorum, sed est prius naturaliter omnibus istis et secundum prioritatem naturalem est 'quod quid est'.

20 Ordinatio II, 3, 1, 5-6, p. 483: omnis entitas quidditativa - sive partialis sive totalis-alicuius generis est de se indiferens 'ut entitas quidditativa' ad hanc entitatem et illam, ita quod 'ut entitas quidditativa' est naturaliter prior ista entitate ut haec est, et ut prior naturaliter, sicut non convenit esse hanc, ita non repugnat sibi ex ratione sua suum oppositum...

21 Lectura II, 3, 1, 6, p. 282, No. 171:sic est entitas positiva in eadem re a qua accipitur natura specifica, et entitas formaliter alia a qua accipitur differentia ultima individualis, quae est omnino haec cui repugnat omnimoda divisio.

22 Ordinatio II, 3, 1, 6, p. 479, No. 180: ista realitas individui est similis realitati specificae, quia est quasi atus determinans illam realitatem speciei quasi possibilem et potentialem, sed quoad hoc dissimilis, quia ista nunquam sumitur a forma addita, sed praecise ab ultima realitate formae.

23 La unidad real del individuo autónomo producida por la heceidad, la denomina Escoto 'unidad numeral' o perfectísima, superior y más perfecta que la 'unidad menor que la numeral', propia de la naturaleza común, de la materia, de la forma y de otras realidades imperfectas, incapaces, dentro del orden ordinario establecido, de existir solas. 
No queremos dejar de recordar, aunque sea marginalmente, la diferencia fundamental del individuo escotista con respecto al individuo, tal como lo entiende Tomás de Aquino. Para éste, la sustancia individual existente es un compuesto de materia y forma que ha recibido la existencia o, dicho de otra manera, es una forma existiendo en una materia corporal ${ }^{24}$. El ser sustancial, por el que esta sustancia es tal sustancia, proviene del acto de la forma; a este acto formal, se le añade el acto de existir por el que la sustancia sensible o natural existe fuera de sus causas. La forma, en sí misma inteligible y universal, está individualizada por la materia. Todo en el individuo tomista es singular, aunque la forma sea, de suyo, universal o comunicable en el sentido de que, si no hay algo que se lo impida, puede ser recibida por muchos ${ }^{25}$.

\subsection{El universal en Duns Escoto}

\section{Comencemos por entender lo universal como}

«aquello mismo que en razón de alguna identidad es predicable de cualquier individuo de tal manera que cada individuo sea eso mismo, ipsum idem aliqua identitate est praedicabile de quolibet individuo ita ut quodlibet sit ipsum ${ }^{26}$.

La universalidad consiste en que 'algo mismo en razón del alguna identidad' sea predicable de cualquier individuo que, por su parte, 'sea eso mismo'. Lo predicable de cualquier individuo es un concepto que se encuentra obviamente en el entendimiento humano. Pero, a la vez, cada individuo del que se predique ese concepto es, en razón de alguna identidad, eso mismo. Dicho en términos sencillos el universal, de distinta manera, se encuentra tanto en los individuos de los que se predica un concepto como en el concepto mismo predicado de esos individuos. Se da el universal, aunque de distinta manera, tanto en la realidad individual extra-mental como en los nombres y conceptos elaborados por el entendimiento y predicables de los individuos que conforman esa realidad extra-mental.

De hecho, Duns Escoto va a distinguir tres modos de ser universal o tres tipos de universales en un texto difícil, que traducimos ajustados a su sentido. Veamos:

«El universal se toma o puede tomarse en tres sentidos distintos: como intención segunda, la cual es una cierta relación de razón en un predicable y en este sentido significa este nombre universal concreto asi como la universalidad en abstracto. En otro sentido se toma el universal como aquello que es una cosa de primera intención y es denominada por esa intención, pues las segundas intenciones se aplican a las primeras; en este sentido se puede tomar de dos maneras: de una manera, aquello denominado por esta intención (primera) que es como un sujeto remoto y, de otra manera, el sujeto próximo. De la primera manera se dice de la naturaleza absolutamente considerada como universal', debido a que en sí misma no es ésta y a la que no le repugna, en sí misma, ser dicha de muchos; de la segunda manera no es universal a no ser indeterminado en acto, de manera que un inteligible en número pueda ser dicho de todo supuesto ${ }^{27}$.

24 Summa theologica, Ia., q. 85, a. 1, c.: objectum cuiuslibet sensitivae potentiae est forma prout in materia corporali existit.

25 Summa theologica, Ia, q. 3, a. 2, ad 3um: formae quae sunt receptibiles in materia, individuantur per materiam, quae non potest esse in alia, cum sit subjectum substans; forma vero, quantum est de se, nisi aliquid aliud impediat, recipi potest a pluribus.

26 Ordinatio $I I$, dist. 3 , q. 1 , No. 9.

27 Quaestiones subtilissimae in Metaphysicam Aristotelis, VII, q. 18, No.6: distinguendum est de universa1i. Sumitur enim, vel sumi potest tripliciter: quoniam pro intentione secunda quae scilicet est quaedam relatio rationis praedicabili, et hunc respectum significat hoc nomen universale in concreto, sicut et universalitas in abstracto. Alio modo accipitur universale pro illo, quod denominatur ab illa intentione, quod est aliqua res primae 
Si descomponemos el texto en los tres sentidos que puede encerrar el universal, tenemos:

1. El universal se toma, en un primer sentido, como un nombre universal concreto que encierra una universalidad en abstracto y es una segunda intención.

2. En un segundo sentido, se toma el universal como una cosa de primera intención. Este segundo sentido se subdivide en

2.1. El sujeto remoto al que remite esta primera intención, es decir, la naturaleza común, considerada como 'universal' debido a que en sí misma no es ésta y a la que no repugna, en sí misma, ser predicada de muchos.

2.2. El sujeto próximo (o intención primera) en cuanto universal indeterminado en acto.

El triple universal escotista es, según este texto, yendo de lo menos universal a lo más universal:

1. La naturaleza común o universal in re.

2. La primera intención de la naturaleza común en cuanto universal en acto o universal metafísico.

3. La segunda intención o nombre universal concreto. Universal lógico.

Al universal que se encuentra encerrado en la naturaleza común, le llama Duns Escoto universal real o material y no es en sentido estricto universal o predicable de muchos. La universalidad de la naturaleza común se reduce a su absoluta indiferencia y no repugnancia para convertirse ya sea en singular, unida a la heceidad, ya sea en verdadero universal por obra del entendimiento. Duns Escoto explica la universalidad de la naturaleza común, diciendo que

La naturaleza no es, de suyo, universal, sino que la universalidad le acaece a la naturaleza debido a su primera razbn por la que es objeto y existe en la realidad exterior, en donde la naturaleza existe con la singularidad. Esa naturaleza no es, de suyo, determinada a la singularidad, sino que es por naturaleza anterior a esa razón que la contrae a la singularidad y, en cuanto anterior por naturaleza a lo que la contrae, no le repugna ser sin eso que la contrae. $Y$ como el objeto en el entendimiento según esa entidad y universalidad posee un verdadero ser inteligible, así también en la realidad natural según aquella entidad posee un verdadero ser extra mental, y según esa entidad posee una unidad proporcional, que es indiferente a la singularidad, de manera que no le repugna, de suyo, a esa unidad unirse a cualquier unidad singular ${ }^{28}$.

La universalidad de la naturaleza común, existente en la realidad extra mental unida a la heceidad, se reduce a su indiferencia real a la singularidad de manera que no le repugna unirse a cualquier singularidad. Esta indiferencia y no repugnancia de la naturaleza común es la causa de su comunidad por la que puede, en su indiferencia y no repugnancia, unirse a cualquier unidad singular. De igual manera es indiferente a la universalidad de manera que no le repugna convertirse, por obra del entendimiento, en un concepto universal predicable de todos los individuos implicados en ese concepto. Hay que repetir que la naturaleza común no es universal en acto o completo, debido a que no posee la propiedad de poder ser predicada de mu-

intentionis, nam secundae intentiones applicantur primis et sic accipi potest dupliciter. Uno modo, pro illo quod quasi ut subjectum remotum denominatur ista intentione; alio modo pro subjecto propinquo. Primo modo dicitur natura absolute sumpta 'universale' quia non est de se haec et ita non repugnat sibi ex se dici de multis; secundo modo non est universale nisi sit actu indeterminatum, ita quod unum intelligibile numero sit dicibile de omni supposito.

28 Ordinatio II, dist. 3, q. 1, No. 7: secundum illud esse non est natura de se universalis, sed quasi universalitas accidit illi naturae secundum primam rationem eius, secundum quam est objectum ita etiam in re extra, ubi natura est cum singularitate, non est natura illa de se terminata ad singularitatem, sed est prior naturaliter ipso contrahente, non repugnat sibi esse sine illo contrahente. 
chos supuestos o individuos ${ }^{29}$. Es un universal no positivo sino privativo, en el sentido de que a la naturaleza común no le repugna o le es indiferente unirse a una heceidad para constituir un individuo singular.

En segundo lugar, es universal el sujeto próximo o primera intención en la que el universal se encuentra indeterminado en acto y está en potencia próxima para que se diga de cualquier supuesto ${ }^{30}$. Este es el universal metafisico u objeto inteligible de primera intención que remite de inmediato a la naturaleza común de este individuo sensible y concreto. Primera intención se dice aquí del universal en acto, elaborado por el entendimiento agente inmediatamente en unión causal con la naturaleza común que existe en una sustancial natural, unida a la heceidad. A esta primera intención o universal en acto, la llama especie inteligible u objeto inteligible del acto de intelección.

Por último, es universal el nombre universal concreto (y su concepto correspondiente) con su universalidad abstracta, que es segunda intención y es predicable de todos los supuestos encerrados en ese nombre o concepto. Éste es el universal verdadero y completo, cuya característica esencial es ser predicable de cada uno de los individuos abarcados por ese nombre o concepto abstracto. Es el universal lógico. Este universal encerrado en el nombre o en el concepto, por ser de segunda intención, remite en primer lugar al universal en acto o primera intención de la especie inteligible y, en segundo lugar, a la naturaleza común existente en la realidad extra mental, unida a una heceidad.

\subsection{El fantasma o especie sensible}

El fantasma o la especie sensible es la representación formal del objeto individual sensible producida por la imaginación, una vez que ese objeto sensible ha afectado los órganos de nuestros sentidos ${ }^{31}$. El fantasma o especie sensible es el producto intencional de nuestra imaginación a partir de la afección de un individuo sensible exterior sobre los órganos de nuestros sentidos. El fantasma es ya el resultado del trabajo unificador de la imaginación a partir de la multiplicidad de impresiones sensoriales recibidas por nuestros sentidos del objeto externo. Igual que el objeto sensible representado, el fantasma es singular, sensible y extenso ${ }^{32}$. El fantasma es singular, porque si fuera de otra forma, v.g. universal, no podría ser la representación del individuo sensible. Es igualmente sensible, por ser producto de la facultad imaginativa que es, a su vez, sensible. Y al ser sensible y singular, tiene que ser èxtenso.

Pero el fantasma, como representativo del objeto individual sensible, tiene que representar al individuo sensible en su totalidad, es decir, tiene que representar tanto a la naturaleza común como a la heceidad, elementos reales componentes de todo individuo. En el fantasma o especie sensible de la imaginación está representado tanto el elemento común e indiferente de todo individuo como su elemento individualizante. El elemento común o naturaleza común es, como ya sabemos, una realidad imperfecta con una unidad propia menor que la numeral o del individuo, la cual, de suyo, es indiferente y no tiene repugnancia para ser singular en el individuo sensible o ser universal en el entendimiento. El elemento singular es la heceidad o cuasi

29 Ordinatio $I I$, dist. 3, q. 1, No. 9: sed tale commune non est universale in actu, quia deficit ei illa differentia, secundum quam completive universale est universale, secundum quam scilicet ipsum idem aliqua identitate est pracdicabile de quolibet individuo, ita quod quodlibet sit ipsum.

30 Ordinatio II, dist. 3, q.1, No. 8: universale in actu est illud quod habet unitatem indifferentem, secundum quam ipsum idem est in potentia proxima, ut dicatur de quolibet supposito...

31 Ordinatio I, dist. 3, pars 3, q. 1, p. 215-216, No. 357: phantasma... secundum totam virtutem suam repraesentat objectum ut singulare virtute phantasticae, quia tunc est actualis imaginatio illius objecti in singulari.

32 Ordinatio I, dist. 3, pars 3, q. 1, p. 216-217, No. 359: ...ille terminus realis non recipitur in phantasmate, quia illud receptum esset extensum et ita intellectus agens non transferret ab ordine in ordinem. 
forma, causante de que la sustancia individual sea ésta, indivisible y distinta de las demás sustancias individuales de la misma especie. En el fantasma se encuentra, por igual, tanto lo que nos comunica como lo que nos diferencia de los demás individuos de la misma especie, es decir, aquello que nos singulariza y que nos hace absolutamente indivisibles y distintos de todos los demás.

El fantasma, en cuanto objeto intencional sensible y singular, no puede representar más que a la realidad singular sensible. No puede, en consecuencia, representar a una realidad universal porque eso, de alguna manera, encierra una contradicción. El objeto intencional representante tiene que ser de la misma naturaleza formal que el objeto representado. El fantasma o especie sensible es el objeto intencional de la realidad sensible singular y sólo de esa realidad sensible singular ${ }^{33}$.

El fantasma o especie sensible como sensible y resultado, primero, del contacto de los objetos sensibles con los órganos de nuestros sentidos y luego con la imaginación, se corrompe y desaparece por obra de otro fantasma formalmente contrario o por alguna indisposición en el órgano receptivo ${ }^{34}$.

Si comparamos este fantasma escotista con el fantasma de Tomás de Aquino. Para éste, también el fantasma es la semejanza sensible de una cosa particular, elaborada por el sentido interno y la imaginación ${ }^{35}$. Pero, recordemos que la cosa particular o el individuo tomista es un compuesto de materia y forma o, mejor, una forma existente en una materia corpórea. La forma es, de suyo, comunicable o receptible por muchos individuos; la naturaleza común de Escoto, es sólo indiferente o neutra a ser ya sea singular unida a la heceidad ya sea universal por obra del entendimiento.

Con el fantasma o especie sensible termina el momento sensible del proceso unitario del conocer objetos de la experiencia sensible. El paso o salto de este momento sensible y singular al momento del conocimiento inteligible y universal constituye la abstracción. Veamos cómo se produce.

\subsection{Producción de la especie inteligible}

Para Duns Escoto, la experiencia cotidiana nos dice que nosotros, como seres humanos, poseemos la capacidad de conocer objetos universales, aunque no siempre estemos conociendo objetos universales. Por eso, va a decir que

«el entendimiento o potencia intelectiva del ser humano unas veces se encuentra en potencia esencial o remota de entender y otras veces se encuentra en potencia accidental $y$ próxima de entender ${ }^{36}$.

El paso o cambio de la potencia remota a la potencia próxima de entender, se debe a la adquisición de una forma por medio de la que una representación del objeto, en cuanto inteligible, se presenta al entendimiento. Representación inteligible del objeto, a la que llama especie

33 Ordinatio I, dist. 3, pars 3, q. 1, p. 216, No. 357,: tunc non potest phantasma repraesentare objectum sub alia ratione repraesentabilis.

34 Ordinatio I, dist. 3, pars 3, q. 1, p. 238, No 391: species sensibilis ita est in organo quod corrumpitur per contrarium formaliter, vel per dispositionem in susceptivo disconvenientem tali formae.

35 Summa theologica, Ia., q. 85, a. 1, ad 3um: phantasmata, cum sint similitudines individuorum, et existunt in organis corporeis...

36 Commentarium in Librum I Sententiarum, dist. 3, q. 6, p. 233: intellectus quandoque est in potentia propinqua et accidentali ad intelligendum, qui prius fuit in potentia essentiali et remota... ista mutatio quae fit ad talem potentiam propinquam, videtur esse ad aliquam formam per quam objectum intelligibile est praesens intellectui, quae forma est prior naturaliter actu intelligendi... 
inteligible. La facultad intelectiva o entendimiento es la capacidad que tiene el ser humano de conocer representaciones inteligibles o universales de objetos; capacidad, entendida como remota y esencial de todo ser humano. Pero, para que un acto de intelección se produzca y esa capacidad intelectiva se active o, como Duns Escoto dice, se coloque en potencia próxima para producir conceptos universales, es preciso que el entendimiento se encuentre en presencia de una representación inteligible o universal de un objeto, es decir, que una especie inteligible esté presente al entendimiento. Sin una representación inteligible o especie inteligible, no puede darse un acto de intelección ${ }^{37}$.

Por eso, las distintas opiniones que obvian la presencia de una especie inteligible, como paso previo al acto de intelección, le parecen falsas por el hecho de que rebajan o envilecen (vilificant) la naturaleza del alma. A ese ámbito envilecedor de la potencia intelectiva del alma, pertenecen sus coetáneos Enrique de Gante y Godofredo de Fontaines en su intento de explicar el conocimiento inteligible, sin echar mano de la especie inteligible y eliminar, de esa forma, la necesidad del entendimiento agente.

Obviar la especie inteligible, supone que el objeto del entendimiento y causa de la intelección es, en ese caso, directamente el fantasma producido por la imaginación, como quiere Godofredo de Fontaines. El fantasma sensible y extenso, en ese caso, causaría la intelección inteligible y universal, lo que es imposible, debido a que lo más imperfecto no puede causar lo más perfecto. El fantasma, repite incesantemente, ni es un objeto inteligible ni puede ser representativo de un objeto inteligible o universal. El fantasma representa, como hemos dicho, al individuo, al singular, producido por el órgano de la fantasía o imaginación y no puede, a la vez, representar el universal ${ }^{38}$. Es cierto que el fantasma, al representar al individuo, encierra en esa representación tanto a la naturaleza común como a la heceidad. Pero esa naturaleza común encerrada en el individuo y en el fantasma como su representación, por estar modificada y singularizada por la heceidad, no se encuentra, en términos escotistas, suficientemente indiferenciada o, mejor, universalizada. Por eso, es necesario la actividad del entendimiento agente para que, en unión de la naturaleza, produzcan un ser u objeto inteligible, absolutamente indiferenciado y verdaderamente universal ${ }^{39}$. En eso consiste la abstracción para Duns Escoto: el salto del fantasma $u$ objeto intencional sensible al objeto intencional inteligible, llamado también especie inteligible o universal en acto. El salto del fantasma a la especie inteligible.

Hemos dicho que, para pasar de la potencia remota y esencial del conocer intelectivo a la potencia próxima y accidental del conocer, es preciso la presencia del objeto inteligible universal o de la especie inteligible. Pero para que la especie inteligible esté presente, es preciso, antes, producirla. Producirla supone el salto del fantasma u objeto intencional sensible y singular al objeto intencional inteligible y universal o especie inteligible. Dos causas unidas o dos concausas son señaladas por Duns Escoto en la producción de la especie inteligible u objeto inteligible universal con el que el entendimiento se coloca en disposición próxima al acto último de la intelección o producción del concepto universal predicable de muchos individuos: el fantasma y el entendimiento agente ${ }^{40}$. El fantasma, sólo, no puede ser causa efectiva de la

37 Ordinatio I, dist. 3, pars 3, q. 1, p. 228, No.375: ergo negando speciem intelligibilem, nihil in intellectiva erit sufficienter natum gignere actum intelligendi...

38 Commentarium in Librum I Sententiarum, dist. 3, q. 6, No. 5, p. 236: ergo phantasma quod de se repraesentat objectum sub ratione singularis, non potest ipsum repraesentare sub ratione universali.

39 Lectura I, dist. 3, pars 3, q. 1, p. 336, No. 277: intelligendo commune in singulari non intelligitur sub omni sua indifferentia; ideo aliter oportet universale esse praesens intellectui quam in suo singulari, quia aliter non esset praesens intellectui ipsum universale sub propria ratione sua secundum totam suam indifferentiam.

40 Ordinatio I, dist. 3, pars 3, a. 1, p. 232, No.381: objectum non est causa totalis gignens respectu intelligibilis speciei, quia cum ipso agit intellectus agens, sicut alia partialis causa, et ideo genitum ab istis duobus potest repraesentare objectum sub opposita ratione singularitatis, quae est ratio gignentis. 
especie inteligible porque, en ese caso, el efecto inteligible y universal sería más perfecto que su causa singular y sensible. Tampoco el alma intelectiva o entendimiento puede, sola, ser causa efectiva de la especie inteligible, porque, en ese caso, sería difícil explicar tanto la objetividad del conocimiento intelectivo como la voluntariedad de nuestros actos de conocer. El fantasma y el entendimiento agente, unidos, son, sin embargo, necesarios y suficientes; son la causa total de la producción del objeto inteligible o especie inteligible ${ }^{41}$. Del fantasma hereda la especie inteligible la objetividad o semejanza con el objeto conocido; del entendimiento agente recibe la cognoscibilidad o inteligibilidad como universal en acto. Duns Escoto dirá que la especie inteligible

«es la imagen de quien la produce y el objeto presente bajo la razón de cognoscible o de representado... por la especie está el objeto presente bajo la razón de cognoscible» ${ }^{42}$.

Pero el fantasma u objeto intencional sensible producido por la fantasía o imaginación, representa los dos elementos de la sustancia natural, a saber, la naturaleza común y la heceidad. Por eso, para aclarar totalmente cómo el fantasma es concausa de la especie inteligible, Duns Escoto dirá expresamente

«el entendimiento agente en concurso con la naturaleza de algún modo indeterminada de la cosa, es la causa integra efectiva del objeto en el entendimiento posible según su ser primero, y esto según la completa indeterminación del universal» ${ }^{43}$.

Es el fantasma en cuanto representa la naturaleza común, ya de algún modo indeterminada en la realidad, la causa concurrente con el entendimiento agente para producir la especie u objeto inteligible. De la razón de la naturaleza común, dice Escoto, que es la razón de la producción de la especie, ratio gignendi speciem ${ }^{44}$. La naturaleza común, en su comunidad e indiferencia, encierra en potencia al universal y es ya, de algún modo, indeterminada. Bajo la acción concurrente del entendimiento agente y de la naturaleza común, representada en el fantasma, se producirá la especie inteligible o realidad intencional completamente indeterminada y con la universalidad en acto. El entendimiento agente y el fantasma, como representante de la naturaleza común, son las dos causas únicas y efectivas de la especie inteligible; pero la causa más principal es el entendimiento agente - intellectus agens est principalior causa quam phantasma - por ser ontológicamente más perfecta y, en consecuencia, más activa. De hecho, el entendimiento agente inicia el movimiento o la acción para la producción de la especie inteligible y el fantasma colabora en dicha acción a manera de causa cuasi instrumenta ${ }^{45}$. Duns

41 Ordinatio I, dist. 3, pars 3, q. 3, p. 335, No. 563: ad primum autem actum agit intellectus agens cum phantasma, et ibi intellectus agens est principalior causa quam pahantasma, et ambo integrant unam totalem causam respectu speciei intelligibilis.

42 Ordinatio I, dist. 3, pars 3, q. 1, p. 232-233, No. 382: Per illam speciem genitam, quae est imago gignentis, est objectum praesens sub ratione cognoscibilis seu repraesentati... per speciem est objectum praesens sub ratione cognoscibilis.

43 Quaestiones subtilissimae in Metaphysicam Aristotelis, VII, q. 18, No. 8: intellectus agens concurrens cum natura aliquo modo indeterminata ex re, est causa integra effectiva objecti in intellectu possibili secundum esse primum, et hoc secundum completam indeterminationem universalis.

44 Ordinatio $I$, dist. 3, pars 3, q. 1, p. 231-232, No. 381: ... quia ratio gignendi speciem in sensu non est singularitas, sed ratio naturae. Ideo generaliter respondeo quod quando species gignitur ab aliquo sicut a totali causa, repraesentat ipsum sub illa ratione sub qua gignitur, loquendo 'de ratione gignendi'...

45 Lectura I, dist.3, pars 3, q.3, p. 373, No. 382-383:in ista igitur motione qua objectum efficitur praesens intellectui, intellectus agens est causa principalior non mota... sicut igitur in prima motione intellectus prius movet quam phantasma, et phantasma movet ad motionem intellectus agentis, sic in secunda motione intellectus prius movet quam objectum.

Señalar al fantasma como concausa cuasi instrumental de la especie inteligible se deriva de la permanente analogía que Escoto hace entre el primer momento y el segundo de la intelección. Ver Nota 61. 
Escoto dice del fantasma que es, en unión del entendimiento agente, causa efectiva o eficiente de la especie inteligible.

¿Es la especie inteligible la transformación del fantasma que naturalmente lo antecede, o es una realidad nueva, superior y distinta del fantasma? Para Duns Escoto, no cabe duda que la especie inteligible y universal en acto es una realidad nueva, superior y distinta del fantasma. Habla de que el entendimiento agente transfiere de un orden a otro orden, «intellectus agens transfert de ordine in ordinem», del orden sensible del fantasma al orden inteligible de la especie (Ordinatio I, No. 359). La especie inteligible no puede ser la transformación del fantasma porque posee características distintas, incluso contradictorias. Mientras el fantasma es un objeto intencional singular, sensible y extenso, la especie inteligible es un objeto intencional universal, inteligible y absolutamente inextenso. Es cierto que la especie inteligible se asemeja al fantasma como representativo de la naturaleza, debido a que la naturaleza común, representada en el fantasma, es una de las dos causas efectivas, si bien es menos perfecta que la otra causa, el entendimiento agente. La especie inteligible universal es una entidad intencional nueva y distinta del fantasma. Por eso, no nos parece preciso el uso de expresiones como decir que «el entendimiento recibe efectivamente del fantasma una especie inteligible que está allí formalmente por medio de una denudación ${ }^{46}$, que hace pensar en que la especie inteligible viene ya inteligible del fantasma. Del fantasma el entendimiento no recibe la especie inteligible por medio de una denudación. La especie inteligible es el efecto producido por el entendimiento agente como causa principal y por el fantasma como concausa cuasi instrumental.

Finalmente es necesario decir que este primer momento del conocimiento intelectivo, en el que se produce la especie u objeto inteligible, termina con la presencia de esa especie inteligible, ya universal en acto, en el entendimiento posible ${ }^{47}$. Con la producción por parte del entendimiento agente de la especie inteligible, universal en acto, con el concurso del fantasma, como representativa de la naturaleza común o universal en potencia, y con la presencia de dicha especie inteligible en el entendimiento, el entendimiento ha pasado de ser potencia esencial y remota a ser potencia accidental y próxima de la intelección. La especie inteligible, recordemos, es una intención primera, es decir, es la representación inteligible inmediata del objeto sensible representado en el fantasma. La intelección será el segundo momento del conocimiento intelectivo y, por tanto, una intención segunda, ya que remite en primer lugar a la especie inteligible o primera intención y sólo, de una manera mediata y a través de la especie inteligible, al objeto sensible representado en el fantasma.

Tomás de Aquino denomina, igual que Escoto, a la producción de la especie inteligible abstracción a partir del fantasma o imagen sensible de la sustancia natural. El fantasma, ya lo sabemos, es la imagen de algo individual o compuesto de materia y forma. La forma es, de suyo, comunicable o receptible por muchos individuos, es el universal in re; la materia cuantificada, el principio de individuación por el que la forma se convierte en esta forma existente en esta materia corporal. La abstracción es descrita como una iluminación del entendimiento agente sobre el fantasma, lo que conlleva la des-materialización y des-individuación de la forma ${ }^{48}$. En el proceso de abstracción por parte del entendimiento agente -causa eficiente y

46 Boulnois, Olivier, «Reelles intentions: nature commune et universaux selon Duns Scot», Revue de Métaphysique et Morale, Janvier-Mars, 1992, p. 29: L'intellect reçoit en effet du phantasme une espèce intelligible, qui y est formellement présente par dénudation

47 Ordinatio I, dist. 3, pars 3, q. 1, p. 223, No. 366: agentia talis praesentiae objecti —scilicet phantasma et intellectus agens - sunt sufficienter approximata intellectui possibili, et agunt per modum naturae, et ita causant necessario in illo illud cuius ipse est receptivus.

48 Summa theol., Ia., q. 85, a. 1, ad 4um: phantasmata et illuminantur ab intellectu agente; et iterum ab eis, per virtutem intellectus agentis species intelligibiles abstrahuntur. Illuminantur quidem, quia...ita phantasmata ex virtute intellectus agentis redduntur habilia ut ab eis intentiones intelligibiles abstrahantur. Abstrahit autem intellectus agens species intelligibiles a phantasmatibus, inquantum per virtutem intellectus agentis accipere possumus in nostra consideratione naturas specierum sine individualibus conditionibus, secundum quarum similitudines intellectus possibilis informatur. 
formal-; el fantasma viene a ser la materia o causa material a partir de la que se produce la especie inteligible o forma inteligible ${ }^{49}$. La des-individuación de la forma en el proceso de abstracción entraña conocer la naturaleza específica de la cosa, sin tener en cuenta sus principios individuantes, o simplemente considerar la naturaleza de las cosas de una manera universal. La especie inteligible es una nueva forma, inteligible y universal, producida por el entendimiento a partir del fantasma y por medio de la des-materialización y des-individuación de la forma que se encuentra en el fantasma. Nueva forma que viene a ser un accidente del entendimiento posible en donde es recibida.

De acuerdo a esta doctrina, hablar de abstracción en la producción de la especie inteligible en Duns Escoto, es hablar de una acción del entendimiento agente distinta de la llevada a cabo por el entendimiento agente en Tomás de Aquino. En éste el entendimiento agente ilumina el fantasma lo que conlleva des-materializarlo y des-individualizarlo. En Escoto, por el contrario, no se da des-materialización ni des-individuación. Lo que sí se da, es verdadera universalización, ya que la naturaleza común representada en el fantasma está dotada sólo de indiferencia y por la acción del entendimiento agente se produce una nueva forma, la especie inteligible, totalmente universal o universal en acto. La forma del fantasma tomista -en sí misma universal, inteligible y comunicable a muchos - se encuentra más cercana de la especie inteligible que la naturaleza común, indiferente y neutra de Escoto. En el fantasma tomista existe ya el universal aunque rodeado de razones individuantes, como afirma el Cardenal $\mathrm{Zi}$ gliara ${ }^{50}$. El entendimiento agente en Escoto parece, por tanto, más activo que el entendimiento agente tomista $^{51}$.

\subsection{Producción de la intelección o del concepto y del nombre predicable de muchos individuos}

Con la presencia de la especie inteligible en el entendimiento, nos encontramos en potencia próxima y accidental para producir la intelección actual o el nombre y el concepto predicable de muchos individuos de la misma especie. Tenemos, por tanto, las dos causas necesarias y suficientes para la intelección en acto, a saber, el entendimiento y la especie inteligible que constituyen su causa íntegra ${ }^{52}$. Con la intelección el entendimiento posible recibe y pasa a estar en posesión de la especie inteligible, que es el objeto en cuanto inteligible o como universal en

49 Summa theol., Ia., q. 84, a. 6, c: sed quia phantasmata non sufficiunt immutare intellectum possibilem, sed oportet quod fiant intelligibilia actu per intellectum agentem; non potest dici quod sensibilis cognitio sit totalis et perfecta causa intellectualis cognitionis, sed magis quodammodo est materia causae.

50 Summa Philosophica, Lyon-Paris, 1884, vol. II, p. 288: universale est in sensibili imaginato, quamvis circumscriptum rationibus individuantibus. Ergo phantasma non ratione sui, sed ratione universalis 'separatim' sumpti a suis notis individuantibus agere in intellectum potest eumque determinare ad intellectionem objectivam illius universalis.

51 Bettoni Efrem va a seguir, con respecto a la mayor actividad del entendimiento escotista, una senda zigzagueante. Comienza afirmando que el proceso abstractivo en Tomás de Aquino es más difícil, debido a que es el paso de lo totalmente individual al universal, mientras que en Duns Escoto el paso es más fácil y corto pues se pasa del universal material o físico al universal metafísico primero y luego al universal lógico. Líneas más tarde matizará, sin embargo, que la actividad del entendimiento para Duns Escoto es más decisiva y profunda. Ver: Bettoni, Efrem, «Il processo astrattivo secondo Duns Scoto», Studi Francescani, Firenze, vol. XXXVIII, luglio-Diciembre 1941, No. 3-4, p. 143: ...il contributo e il lavoro dell' intelletto era maggiore per el dottore domenicano di quello che gli riconosceva il dottore francescano...bisogna dire che l'attivitá dell'intelletto per Duns Scoto e piu decisiva e profonda.

52 Ordinatio I, dist. 3, pars 3, q. 2, p. 292, No. 494: si ergo nec anima sola nec objectum solum sit causa totalis intellectionis actualis -et illa sola videntur requiri ad intellectionem- sequitur quod ista duo sunt una causa integra respectu notitiae genitae. 
acto. Entender algo significa recibir su intelección. El entendimiento entiende formalmente cuando recibe la intelección ${ }^{53}$. La intelección, en cuanto que es aquello por lo que (quo) formalmente entendemos, es una forma recibida por el entendimiento $y$, por tanto, es un accidente. El entendimiento posible, en cuanto receptor de esa forma accidental de la intelección, es una forma substancial o algo en acto primero, aunque la potencia intelectiva o entendimiento, con relación a la forma accidental de su intelección que va a recibir, no esté en acto sino en potencia ${ }^{54}$.

En el momento primero de la intelección, son el entendimiento agente y el fantasma, como representativo de la naturaleza común, las causas de la producción de la especie inteligible. En este segundo momento de la intelección, son causas esenciales el entendimiento posible y la especie inteligible, el entendimiento posible y el objeto inteligible o universal en acto. Ambas son esenciales: el entendimiento está siempre dispuesto a recibir cualquier intelección, pero necesita de la presencia de la especie u objeto inteligible para que se siga el efecto de la intelección. Sin la especie no hay intelección ${ }^{55}$. El primer momento de la intelección por medio del cuál se produce la especie inteligible, mueve de inmediato al entendimiento a producir el segundo momento de la intelección o universal completo o lógico ${ }^{56}$. En el segundo momento, el entendimiento posible recibe y contempla la especie inteligible del momento primero. El producto de este segundo momento, cuyas causas son el entendimiento posible y la especie inteligible, es la intelección última y su nominación, por medio de la que la intelección recibe un nombre universal concreto, como expresión linguística del universal completo ${ }^{57}$. Universal completo que encierra como propiedad esencial el ser predicable de todos los supuestos que sean lo expresado por esta intelección. De estas dos causas, ambas ordenadas y perfectas en su causalidad para producir el acto de intelección, el entendimiento es simplemente más perfecta que la especie ${ }^{58}$. El entendimiento posee una indeterminación ilimitada para entender objetos, pero esta especie determinada, con su presencia, hace que entienda o reciba esta intelección o la intelección de este objeto concreto ${ }^{59}$. El entendimiento, como causa más principal,

53 Ordinatio I, dist. 3, pars 3, q. 2, p. 321, No. 537.: formaliter autem intelligimus intellectum in quantum recipit intellectionem...intellectio in quantum est quo formaliter intelligimus, est forma quaedam recepta in intellectu.

54 Op. Cit.,..p. 322-323, No. 541: intellectio seu species intelligibilis non est forma substantialis, sed accidens; ergo quod est immediate receptivum illius, est aliquid in actu substantiali.... intellectus ergo possibilis, secundum quod eșt illud in quo recipitur forma intelligibilis vel intellectio, vel illud secundum quod species recipitur in anima, non erit purum potentiale, sed erit aliquid in actu primo, licet ipse respectus potentiae non sit aliquid in actu...

55 Op. Cit.,, p. 311, No. 523: anima non semper est in actu respectu cuiuscumque intellectionis - cum tamen ipsa sit receptiva cuiuscumque intellectionis, et ipsa sit sibi approximata et non semper impeditur-concluditur ipsam non esse totalem causam activam, sed aliquid aliud; illud 'aliud' concluditur esse objectum, quia eo praesente sequitur effectus, eo non praesente non potest haberi.

56 Lectura I, dist. 3, pars 3, q. 2-3, p. 374, No. 384: dico igitur quod intellectus... movet secunda motione quia movetur a prima motione, qua objectum fit sibi praesens; et adhuc prius movetur ab intellecto agente tunc quam a phantasmate.

57 Quaestiones subtilissimae in Metaphysicam Aristotelis, VII, q. 18, No.6: distinguendum est de universali. Sumitur enim, vel sumi potest tripliciter: quoniam pro intentione secunda quae scilicet est quaedam relatio rationis praedicabili, et hunc respectum significat hoc nomen universale in concreto, sicut et universalitas in abstracto

58 Ordinatio I, dist. 3, pars 3, q. 2, p. 294-295, No. 498,: sunt ergo casuae essentialiter ordinatae, et ultimo modo, videlicet quod una est simpliciter perfectior altera, ita tamen quod utraque in sua propria causalitate est perfecta, non dependens ab alia.

Ordinatio $I$, dist. 3 , pars 3 , q. 3, p. 333, No. 559: videtur quod pars intellectiva habeat principaliorem causalitatem respectu intellectionum modo nobis naturaliter convenientium.

59 Ordinatio I, dist. 3, pars 3, q. 2, p. 326, No. 545: intellectus... est indeterminatio actualitatis quasi illimitatae, et ideo non determinatur per formam quae sibi sit ratio determinata agendi, sed tantummodo per praesentiam objecti, circa quod determinatum nata est esse determinata intellectio. 
actúa en primer lugar y la especie co-actúa ${ }^{60}$ con el entendimiento a manera de un cuasi instrumento del que se aprovecha el entendimiento posible para su acción y de manera análoga a como actúan la mano y el cuchillo para cortar un leño ${ }^{61}$.

El hecho de que el entendimiento sea una causa esencial de la intelección más perfecta que la especie, no quiere decir que ésta, en su causalidad, dependa del entendimiento. Como ambas son perfectas en su causalidad, son, en consecuencia, independientes en su causalidad la una de la otra. Cada una tiene su propia razón de causalidad y co-actúa, de acuerdo a su razón de causalidad, en la producción de la intelección, aunque entre ambas se da una unidad de orden o de preeminencia según la cual el entendimiento es una causa más perfecta y superior y, en consecuencia, inicia el movimiento o la acción a la que concurre la especie ${ }^{62}$. De la especie inteligible, recibe la intelección su semejanza unívoca y formal con el objeto, por ser la causa de la objetividad de la intelección; del entendimiento, su semejanza virtual o equívoca con su universalidad de predicación ${ }^{63}$.

En los textos de Duns Escoto encontramos, por un lado, que el entendimiento posible es receptor y pasivo con respecto a la especie inteligible recibida; por otro lado, en este segundo momento de la intelección, el entendimiento o parte intelectiva aparece como activo (»agit pars intellectiva, animam non esse totalem causam activam») y actuante y no como movido por la especie ${ }^{64}$. Esta aparente contradicción nos hace pensar que, efectivamente, el entendimiento o parte intelectiva desempeña la doble función de pasivo, en cuanto receptor de la especie inteligible, y de activo, en cuanto que a esa forma inteligible la contempla para nombrarla y, convertida en nombre, la hace predicable de muchos individuos de una misma especie. Que esta función activa de la intelección corresponda al entendimiento posible o, más bien, al entendimiento agente, es algo que no le preocupa a Duns Escoto, sive intellectus agens sive possibilis, non curo modo (Ver nota 64).

La intelección como concepto singular y nombre singular, aunque universal en su predicabilidad de muchos individuos, es el objetivo último del conocimiento humano. Es una intención segunda porque remite de inmediato a la especie inteligible, que es una intención primera, y sólo de una manera mediata remite al fantasma y objeto intencional sensible. Este universal completo es 1lamado por Duns Escoto, universal lógico, distinto del universal metafísico, que es la especie inteligible, y del universal real o material, que es la naturaleza común.

60 Lectura I, dist. 3, pars 3, q. 2-3, p. 372, No. 380: illud est causa perfectior quod primo agit et ad cuius actionem agit illud; sed intellectus agit ad intellectionem et objectum coagit, et non e converso.

61 Ordinatio $I$, dist. 3, pars3, q. 3, p. 334, No. 562: videtur enim intelligibilium nobis naturaliter intellectorum species in intellectu esse quasi instrumentum ipsius intellectus, non motum ab intellectu ut agat,...sed quo intellectus utitur ad suam actionem.

En Lectura I, disp. 3, pars 3, q.2, p.369-370, No.372, compara la acción concurrente del entendimiento posible y de la especie inteligible con la acción concurrente de la mano y el cuchillo para cortar un leño: potentia motiva utitur cultello ad scindendum lignum:

62 Ordinatio 1, p. 296, No. 503: in quocumque ordine causarum, oportet ponere respectu unius effectus unam per se causam, et unam rationem per se causandi (ita intellectus in suo ordine causalitatis est unus, et habet unam rationem formalem causandi, et species vel objectum in suo ordine causandi est una causa specialis, et habet unam rationem causandi), sed non oportet totalem causam prout complectitur omnes causas partiales, habere unam rationem causandi nisi unitate ordinis, quod.... est per se.

Lectura I, dist.3, pars 3, q.3, p.373, No. 383: sic in secunda motione intellectus prius movet quam objectum; immo objectum commovet ad motionem intellectus.

63 Ordinatio I, dist. 3, pars 3, q. 2, p. 325, No. 541: quando concurrunt duae causae, sufficit in propinquiore similitudo formalis, et in remotiore virtualis sive similitudo aequivoca, et ita intellectus, quasi causa superior, virtualiter assimilatur intellectioni, species, quasi causa propinquior, quasi univoce et formaliter assimilatur ei.

64 Textos en los que el entendimiento aparece como pasivo y receptor, hemos citado varios. Veamos un texto en el que el entendimiento aparece como activo: «ad secundum actum agit pars intellectiva (sive intellectus agens sive possibilis no curo modo) et species intelligibilis sicut duae partiales causae, et ibi agit pars intellectiva non mota a specie, sed prius movens, id est quasi agens ut species sibi coagat» (Ordinatio I, dist. 3, pasrs 3, q. 3, p. 335, No. $563)$. 
Para Tomás de Aquino, el entendimiento posible se compara con respecto a las formas inteligibles como la potencia con respecto al acto. Una potencia que se asemeja a la tabla rasa del filósofo en donde recibe las especies o formas inteligibles, que son su acto ${ }^{65}$. La especie inteligible es, en cuanto forma, acto que, al ser recibido, por la potencia pasiva del entendimiento produce la intelección. La acción de entender se deriva, según esta descripción, más del objeto, como acto, que del entendimiento que es potencia pasiva ${ }^{66}$. La reflexión del entendimiento sobre sí mismo y la contemplación de la especie o forma inteligible recibida, produce la verdadera intelección o concepto verdaderamente universal. La especie inteligible es aquello por medio de lo que (quo) entendemos ${ }^{67}$. Lo conocido o entendido es la cosa externa en su naturaleza específica de la que la especie inteligible es una semejanza. El universal abstracto es, para el Aquinate, doble: la naturaleza específica de la cosa y la abstracción o universalidad de la misma ${ }^{68}$. La naturaleza misma que es entendida o abstraída se da en los singulares; pero su intelección misma y su abstracción, o su intención de universalidad se dan en el entendimiento. La humanidad entendida existe sólo en este o aquel hombre; per(Ver nota 64)o que la humanidad sea entendida sin sus condiciones individuantes, lo que significa abstraerla, y su consiguiente intención de universalidad se producen por la acción del entendimiento en el que se da una semejanza de la naturaleza específica y no de los principios individuantes ${ }^{69}$. El universal es, para Tomás de Aquino, en primer lugar la naturaleza específica abstraída de sus condiciones individuantes por obra del entendimiento agente $y$, en segundo lugar, su concepto y su nombre predicable de muchos.

Para Duns Escoto, la intelección es el producto de dos causas: del entendimiento y de la especie inteligible. Pero, la causa más perfecta de la intelección, —en la especie inteligible era el entendimiento agente- es ahora el entendimiento pasivo, debido a que posee una capacidad ilimitada para entender objetos de la experiencia; esta capacidad es su potencia esencial y remota con respecto a la intelección ${ }^{70}$. La presencia de la especie inteligible con su universalidad en acto, desencadena esa potencia remota y esencial del entendimiento posible y lo hace

65 Summa theologica Ia, q. 79, a. 2, c: unde omnis intellectus creatus, per hoc ipsum quod est, non est actus omnium intelligibilium, sed comparatur ad ipsa intelligibilia sicut potentia ad actum... intellectus humanus, qui est infimus in ordine intellectuum, et máxime remotus a perfectione divini intellectus, est in potentia respectu intelligibilium, et in principio sicut tabula rasa in qua nihil est scriptum...et per consequens intellectus est potentia passiva.

66 Este análisis lleva a Efrem Bettoni a repensar lo dicho anteriormente (nota 51), para llegar a decir que para Sante Tomás a la especie inteligible le compete toda la actividad de la intelección y nuestra facultad de entender es pura potencia: «Cio che fa essere l'atto intellettivo, la sua causa formale e dunque l'oggetto e la species intelligibilis a cui percio compete tutta l'attività, mentre la nostra facoltà e pura potenza. Ver Bettoni, E., «Oggetto e sog. getto nell 'atto intellettivo secondo Duns Scoto», Studi Francescani, Firenze, (XXXIX), Gennato-Giugno 1942, No. $1-2$, p. 12 .

67 Summa theol., Ia, q. 85, a. 2, c: Species intelligibilis se habet ad intellectum ut quo intelligit intellectus... similitudo rei intellectae, quae est species intelligibilis, est forma secundum quam intellectus intelligit. Sed quia intellectus supra seipsum reflectitur, secundum eandem reflexionem intelligit et suum intelligere, et speciem qua intelligit. Et sic species intellectiva est secundario id quod intelligitur. Sed id quod intelligitur primo est res cuius species intelligibilis est similitudo.

68 Summa theol., Ia., q. 85, a. 2, ad 2 um: cum dicitur uiversale abstractum, duo intelliguntur: scilicet ipsa natura rei, et abstractio seu universalitas. Ipsa igitur natura cui accidit vel intelligi vel abstrahi, vel intentio universalitatis, non est nisi in singularibus; sed hoc ipsum quod est intelligi vel abstrahi, vel intentio universalitatis, est in intellectu.

69 Ibidem, ad 2um: humanitas quae intelligitur, non est nisi in hoc vel in illo homine; sed quod humanitas apprehendatur sine individualibus conditionibus, quod est ipsam abstrahi, ad quod sequitur intentio universalitatis, accidit humanitati secundum quod percipitur ab intellectu, in quo est similitudo naturae speciei, et non individualium principiorum.

70 Ordinatio I, dist. 3, pars 3, 3, p. 333, No. 559:quando causarum ordinatarum altera est indeterminata ad multos effectus, et quasi illimitata, altera autem secundum ultimum virtutis suae determinata ad certum effectum, illa quae est illimitatior et universalior, videtur esse perfectior et principalior. 
entender esta intelección concreta y singular, nombrándola con un nombre singular y lo dota de predicabilidad con respecto a muchos supuestos. El entendimiento pasivo de Escoto posee la capacidad ilimitada de entender infinidad de intelecciones. Al concretar, ante la presencia de esta especie inteligible, su actividad en esta intelección, la nombra y dota de predicabilidad con respecto a muchos supuestos, lo que supone una actividad de unificación y de aplicación múltiple que hace del entendimiento pasivo escotista una facultad sumamente activa ${ }^{71}$. La naturaleza específica, no es jamás universal, sino sólo indiferente y, en consecuencia, el universal en acto queda reducido a: 1) la especie inteligible (universal metafísico); 2) a su concepto y su nombre (universal lógico) que son predicables de muchos. Para Duns Escoto, el universal pleno queda reducido a sólo conceptos y nombres de esos conceptos. Su tendencia al nominalismo es evidente. Para Tomás de Aquino, el universal abstracto es, en primer lugar, la forma específica sin sus condiciones individuantes, y, en segundo lugar, el concepto y el nombre de esa forma específica que son predicables de muchos individuos.

\section{CONCLUSIÓN}

La existencia del entendimiento agente en el alma humana responde a la necesidad de explicar la formación de los conceptos y los términos universales. Ya para Aristóteles, en el universo físico extra-mental no existía más que lo singular; el universal, por el contrario, pertenece al ámbito del pensar, es decir, de la lógica y del lenguaje. Y la razón de los universales deriva, para Aristóteles, de la carencia para el lenguaje de expresar en términos singulares todo lo que percibe por los sentidos. En el mundo hay infinidad de cosas; en el lenguaje disponemos, sin embargo, de un número limitado de nombres o términos capaces de significar esa infinidad de cosas ${ }^{72}$. En consecuencia, nos vemos obligados a pensar el mundo exterior en grupos en función de la semejanza de las cosas y expresar cada grupo de cosas singulares con un solo nombre. En el proceso de conocer humano se pasa de la infinidad de las cosas singulares a los conceptos y términos universales en número finito. Es con el fin de explicar ese paso de lo singular a lo universal, que Aristóteles, igual que Duns Escoto, echó mano del entendimiento agente, en sí mismo inteligible y activo, como facultad productora de universales. La necesidad de explicar la formación de los conceptos y términos universales, obliga a Duns Escoto a defender la existencia y la acción del entendimiento agente. En la defensa del entendimiento agente, por tanto, Duns Escoto no hace sino seguir los pasos de Aristóteles, de igual manera que antes lo había hecho, entre otros, Tomás de Aquino.

Lo característico de Duns Escoto, como hemos visto, va a ser la explicación que da de la acción abstractiva del entendimiento agente a partir de una concepción original del singular o individuo. En la acción abstractiva entran 3 elementos, a saber, el singular, el universal y el entendimiento humano. Al universal, real o lógico, lo acompañan tanto la comunicabilidad positiva como la predicabilidad: un concepto o término universal expresa algo en lo que muchos comulgan o se comunican y es predicable de muchos. El singular, por el contrario, es incomunicable y no predicable de muchos. La originalidad de Duns Escoto consiste en separar la comunicabilidad positiva del universal real y, reduciéndola a una comunicabilidad privativa, trasladarla no al singular en su singularidad sino a un elemento constituyente del singular, que ni es singular ni universal sino indiferente a ser lo uno o lo otro: la naturaleza común. La na-

71 Ver un examen detallado de la actividad del entendimiento pasivo escotista en: Bettoni, Efrem, «Oggetto e soggetto nell 'atto intellettivo secondo Duns Scoto», Studi Francescani, Firenze,(XXXIX), Gennaio-Giugno 1942, No. 1-2, pp. 27-31.

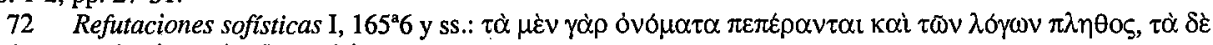

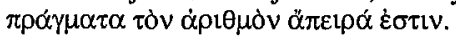


turaleza común o lo formal indiferente, en el individuo singular, resulta ser una realidad extraña que cabalga entre lo singular — no es predicable de muchos-y lo universal privativo - es indiferente y no le repugna comunicarse a muchos individuos-. El singular escotista es un injerto en el que se encuentran todas las propiedades del singular, pero encierra, a la vez, en uno de sus componentes - la naturaleza común - la comunidad o comunicabilidad privativa, a la que no le repugna unirse a cualquier singularidad y comunicarse a muchos singulares. Debido a esta composición del singular - naturaleza común + heceidad—puede decirse, retomando a Boulnois que «la cosa es, en ella misma, singular de pleno derecho. Pero en la cosa singular existente, no hay sólo singularidad: en el singular, todo es singular, pero no todo es pura singularidad ${ }^{73}$.

De esta concepción escotista del singular, resulta que la acción abstractiva del entendimiento agente conlleva unas características propias. La abstracción continuará siendo el paso del singular al universal, pero el paso del singular a partir de su elemento común o naturaleza común que, como sabemos, es, en sí misma, indiferente y a la que no repugna devenir universal, después de haber sido singular, unida a la heceidad en el individuo. El auténtico universal quedará reducido al concepto y a su expresión en un nombre y estará dotado sólo de la posibilidad de ser dicho o predicado de muchos, es decir, de predicabilidad.

La naturaleza común, recogida de una manera intencional en el fantasma o imagen sensible, es el fundamento objetivo del universal completo que es sólo concepto y nombre. Por eso, Escoto dirá de la naturaleza común que es el universal real, mạterial o en potencia. Nosotros lo hemos descrito como universal privativo para significar su esencial indiferencia o no repugnancia ya sea a comunicarse a distintos individuos ya sea a devenir universal lógico y predicable de muchos. El universal completo o lógico será el producto de todo el proceso abstractivo, es decir, el concepto y su nombre, en cuanto son predicables de muchos individuos que se comunican en la naturaleza común.

Entre el fantasma o imagen sensible y el universal completo o lógico, se encuentra la especie inteligible o universal metafísico. Es el entendimiento agente como causa más perfecta, en unión del fantasma como concausa más imperfecta, quien produce la especie inteligible, forma inteligible o universal en acto. Del fantasma recoge la especie inteligible la objetividad o el contenido, del entendimiento recibe la universalidad formal o en acto.

El entendimiento como causa más perfecta, en unión de la especie inteligible como concausa menos perfecta, produce el universal completo o lógico que consiste en recibir la especie inteligible o universal en acto y nombrarlo, de manera que ese nombre sea predicable de muchos individuos que se comunican en la naturaleza común o universal material o potencial. La acción del entendimiento agente consiste, por tanto, en pasar del universal privativo, material o potencial, encerrado en el fantasma al universal lógico, pasando por el universal metafísico. En otras palabras, pasar de la comunidad indiferente de la naturaleza intencional, encerrada en el fantasma, a la predicabilidad del nombre o término absolutamente universal, es decir, al concepto o nombre que puede predicarse de muchos individuos; pasando previamente por la producción de la especie inteligible o universal en acto. El concepto y nombre universal recibe de la especie inteligible su objetividad o contenido intencional; del entendimiento posible, también activo, la auténtica universalidad que consiste en que ese concepto y nombre pueda ser dicho o predicado de muchos individuos.

Para Duns Escoto, el universal completo o lógico existe sólo como concepto con su nombre correspondiente. Con Escoto desaparece todo tipo de universales reales positivos. El único

73 Boulnois, Olivier, «Reelles intentions: nature commune et universaux selon Duns Scot», Revue Métaphysique et de Morale, 97/ 1, Janvier-mars 1992, p. 9: la chose est par elle-même singulière de plein droit. Mais dans la chose singulière existante, il n'y a pas seulement de la singularité: dans le singulier, tout est singulier, mais tout n'est pas pure singularité. 
universal real o material extramental es la naturaleza común, al que nosotros hemos descrito como universal privativo por su indiferencia y no repugnancia a comunicarse realmente a distintos y múltiples individuos singulares. Lo formal, en Duns Escoto, ha perdido la universalidad real positiva para convertirse en la naturaleza común, en sí misma, neutra o indiferente a formar parte, en unión de la heceidad e individualizada por ella, del individuo singular.

Ubicar a Duns Escoto entre los pensadores medievales que defienden el realismo exagerado, al estilo de Remigio de Auxerre o San Anselmo, es tergiversar profundamente su pensamiento. El pensamiento de Escoto con respecto a los universales, habría que definirlo como una posición intermedia entre el realismo moderado de Tomás de Aquino y el nominalismo de Guillermo de Ockham. El universal auténtico o completo, para Duns Escoto, queda reducido a conceptos y nombres. Pero estos nombres no remiten, en última instancia o mediatamente, a ninguna realidad en sí misma universal, sino a una realidad, la naturaleza común, dotada de una indiferencia y no repugnancia que le permitirá individualizarse, unida a la heceidad, o ser concausa del universal indeterminado que es la especie inteligible.

Antonio Pérez-Estévez

Apartado 10.114

Maracaibo (Venezuela) 